\title{
Post-institutional methodology of economic systems analysis: focusing on a regional scale
}

\author{
Daniil P. Frolov \\ Volgograd State University \\ Institute of management and regional economics \\ Volgograd, Russian Federation \\ ecodev@volsu.ru \\ Google Scholar: Daniil P. Frolov
}

\begin{abstract}
The conceptual frame of the post-institutional approach to studying of economic systems connected with overcoming the numerous dogmas and dichotomies which have developed within new institutionalism is presented. The perspective directions of application of this methodology to the analysis of economic processes and institutions at the regional level are proved.
\end{abstract}

Keywords - regional economy, institutions, institutionalization, economic space, institutional configurations, post-institutionalism

\section{INTRODUCTION}

The institutional economic theory is the leading direction in modern economic science, reasonably applying for the status of a mainstream and for a role of a new paradigm of economic policy. At the same time, the competitiveness of institutional methodology in comparison with neoclassical remains undecided. First of all it is connected with the fact that the institutional economics obviously comes under influence of micro-macro dualism which is shown in prolonged discussions: in the theory - about priority of individualistic or holistic interpretations of complex economic processes; in applied areas - about the choice of an optimal variant of regulation between approach "top-down" (state administration) or "bottom-up" (market self-organization). Intermediate, hybrid approaches and options if are considered, in general remain on the periphery of the institutional analysis.

The methodological problems, specific for institutional micro- and macroeconomics, are derivative of backwardness of the multilevel analysis of economic institutions and, respectively, insufficient understanding of inter-level relations. The narrowed representation of multilevel structure of economy is resulted by numerous methodological and practical problems. So, in institutionalism there is no accurate alternative rational-maximizing model of man (individual behavior) which is the base of neoclassics and also the question of interrelation of individuals and institutions in evolution of economic systems keeps high debatability. The mesobases of the institutional theory are almost not developed, institutions of local and regional level are studied extremely poorly, and their role is necessary negligibly low. The institution-driven development of territories still remains poorly operational concept of spatial management and doesn't find practical use.
The institutional paradigm of economic regulation (including theory of reforms) is based on mechanistic concepts of design of institutions, their transplantations and overcomings the arising dysfunctions whereas modern evolutionary ideas have a limited scope. Failures and stalling in use of the institutional theory for the solution of current problems of regional economy and local communities turn out to be consequence of it. Institutional development of economic space of cities and regions and also other territorial structures (networks, clusters, etc.) isn't the autonomous process isolated from the external environment; on the contrary, it is objectively multilevel, interactive process of huge complexity. Therefore researchers face considerable difficulties during elaboration of strategy of the institution-driven development of regions and at design of dynamic institutional mechanisms of regulation of regional social and economic processes.

The most difficult subject of the institutional mesoanalysis negatively corresponds to dysfunctions of the institutional theory with its numerous unilateral and dualistic (dichotomizing) conventions and concepts. Among them limited legal interpretation of institutions as "rules of the game", restrictive interpretation of functions of institutions as limiters of economic behavior of agents, the negativist concept of transaction costs as "friction expenses", lack of the regulatory concept of the transaction sector and obsession on its (poorly comparable among themselves) measurements, a dichotomy of individualistic and holistic methodology of the analysis of institutions, etc. In this regard the purpose of article is development of the conceptual frame of the modernized methodology of the institutional and evolutionary analysis (which is conditionally designated as postinstitutional approach), providing complex overcoming of methodological contradictions of the modern institutional economic theory that will allow to raise significantly extent of conceptualization of institutionalism as base of development of regional strategies and programs.

\section{MATERIALS AND METHODS (MODEL)}

The research offered in article directed to modernization of methodology of the institutional analysis assumes a combination of methods of comparative, critical, dialectic, system and evolutionary approaches to overcoming a monoaspectation, dikhotomies and dogmatism of key concepts of modern orthodox institutionalism. 


\section{RESULTS AND DISCUSSION}

Since 1990th institutionalism quickly gained popularity, was widely used in various fields of social sciences and in fact became a mainstream in all heterodox directions of the economic analysis. At the same time, among institutsionalist defects of methodology and "gray zones" of the research program of institutional science began to be discussed even more often, and the term "post-institutionalism" became a marker of these discussions. In particular, arguments spoke against a stereotype about static character and lag effect of institutional structure of society; excessively homogeneous perception of territorial communities within which institutions are formed was exposed to criticism; need of extension of the institutional analysis out of limits of formal institutions and also accounting of complexity and messiness of the local institutional relations was proved. The special attention was drawn to interpretation of institutions as non-uniform institutional complexes ("alloys", "mixes") with ambiguous functionality which are formed on the basis of tests and mistakes, step-by-step iteration and combination of available resources (general name for such institutional structures is bricolage). There were critical works directly indicating expediency of creation of the new integrative multitheoretical frame of the institutional analysis overcoming traditional dichotomies (for example, opposition of formal and informal institutions, "rules of the game" and "players", etc.) and expanding conceptual stereotypes (for example, obsession with a conservative role of institutions in evolution, artificial data of all intangible resources to institutions, etc.). It is necessary to recognize that as the methodology, and the program of post-institutional researches still have quite fragmentary and amorphous character. But it is important that the post-institutionalism has arisen within the institutional science therefore it is connected not with refusal of institutional approach, but with its deep substantial modernization.

At the same time the post-institutional prospect meanwhile remains quite fragmentary and amorphous. In author's treatment the post-institutionalism represents a working metaphor, characterizing the massif of the perspective trajectories of development of institutional economics connected with denial of the conventional orthodox concepts, development of integrative approaches and the movement to a unifying paradigm of the institutional analysis.

Development of post-institutional methodology is directed to complex overcoming numerous vulnerabilities widely adopted in the economic theory and practice of the "standard model" of institutionalism (including axiomatics and conceptual designs of the new institutional theory and "original" institutionalism) that assumes a number of substantial shifts [1]:

- from exaggeration of a role of separate types of institutions (in particular, easily measurable formal norms within "new new" institutional economics) to judgment of their combinatory and complex nature, removal of an institutional bricolage in the center of analytical and empirical researches:
- from opposition of institutions ("rules of the game") and organizations ("players") to the analysis of institutional configurations and ecosystems, better understanding of a role of internal and external stakeholders in institutional changes of different scale;

- from unilateral interpretation of institutions as factors of inertia and parameters of stability to their reconsideration as drivers (generating factors) of economic evolution and development of a new class realistic and the institutionoriented (i.e. using institutions as explaining variables) evolutionary concepts;

- from obsession with institutions to studying of their systemic relations with other intangible (transactional) resources and development of the polyfactorial methodological approaches considering polymorphism of institutions (in particular, existence of a range of their "soft" and "rigid" forms);

- from destructive and negative interpretation of transaction costs to formation of the positivistic transactional analysis, development of ideas of institutions of transactional development, creation of the concept of institutional mechanisms of regulation of the transaction sector of economy;

- from studying of separate types of steadily inefficient conditions of institutions (market and state failures, dysfunctions at transplantation of institutions, etc.) to development of the uniform theory of institutional anomalies, their multilevel classification and systematization of methods of counteraction by them;

- from institutional concepts with assumption of neutrality of the market environment to conceptualization of a role of marketing in institutional changes and development of marketing technologies of institutional design;

- from ignoring of mesolevel of institutional changes to formation of the analytical device of researches of institutional development of the cities and regions, networks and clusters, sectoral and inter-sectoral systems and also to reconsideration of a phenomenon of institutional thickness of economic space;

- from institution-neutral concepts of technological development to reconsideration of technologies as stakeholder communities united by technologically related institutions and to development of platform approach to institutional policy in the field of regulation of national and regional innovative systems and also innovative territorial clusters [2];

- from opposition of principles of economic policy of a neoclassical mainstream and institutionalism to development of the integrative approach uniting neoclassical, institutional and evolutionary positions in the complete system of regulation;

- from the fragmented set of poorly coordinated principles of institutional policy (policy in the field of transplantation and designing of economic institutions) to formation of uniform methodical system of formation of adaptive institutional strategy for subjects of business, state and society. 
Important mission of post-institutionalism is overcoming developed dichotomies in the field of methodology. In this sense the idea of transition from opposition of methodological individualism and a holizm to the "switching mode" of methodologies among which particular importance is attached to intermediate approaches, in particular, to methodological institutionalism is perspective. This approach in the author's version is understood as methodology of the configurational mesoanalysis of economic systems, i.e. their studying through an analytical prism of institutional configurations - models of interactions of institutions and their stakeholders in concrete economic space. The configurational paradigm of institutional analysis accents non-uniform and internally contradictory nature of complex institutional structures behind which there are always interests of the confronting and interacting actors. Configurational approach to a research of regional economy assumes accounting of multiactor and multifactor nature of this process, influence of various categories of stakeholders (relational and categorial social groups) having the specific interests and the strategy of behavior and integrated into the local system of the formal and informal institutions. This approach convincingly shows that evolution of any region' economy has a little general with linear accumulation of complexity of its institutional device by the principle of the movement from the simple relations of subjects to irregular shapes of the organization. The institutional configuration of regional economy represents bricolage, "scrappy" structure developing on the basis of tests and mistakes when new versions of institutions "accumulate" on old, a large role are played by improvisation of participants, and models of interactions from different spheres (state, business, science, etc.) are with difficulty adjusted to each other during multistep coordination [3].

\section{CONCLUSION}

Institutional researches of mesoeconomy of spatial structures, including regional scale, are still extremely not numerous, come under influence of effect of fetishization of regions (minor attention to an urbanization, characteristic in general for a regional science and economic geography), operate with incompatible interpretations of institutions, show obvious difficulties with measurement (or at least assessment) the level of institutional development of territories and accurate definition of relationships of cause and effect between institutions and development, on the one hand, and between institutions and other endogenous factors of development, - with another, considerably reducing thereby empirical validity of institutional recommendations for regional policy [4]. At the same time the expressed tendency of transformation of the cities and regions in socially responsible multi-stakeholder territorial quasicorporations that obviously demands new (institutional in fact) approaches to strategic planning and management of their social and economic development in which focus there have to be flexible and adaptive formats of the spatial organization of economy - regional networks, clusters, agglomerations, innovative ecosystems, etc. is underestimated [5].

The perspective of influence of institutions on regional economic development, despite would seem high degree of studying, leaves numerous fundamental questions without answers. Recognition of an endogenity of institutions within econometric models still isn't followed by their inclusion as an obligatory component of regional strategic projects and strategies. Besides, researchers state considerable complexity of causal communications between quality of institutions and effectiveness of regional economic policy, existence of methodological and methodical difficulties in the field of measurement and comparison of quality of the institutional environment and separate institutions of regional level. The special debatability characterizes the institutional theory of local reforms: with great difficulty the idea about relativity of "best institutions" concept and limitation of opportunities of institutional transplantation from more developed regions in less developed gains recognition (this thesis is of particular importance for idealists in the field of regional cluster policy). Overcoming the mechanistic approach to management of institutional development of territories connected with a tranplantation, design and elimination of dysfunctions of institutions that is possible on the basis of adaptation of the evolutionary concept of designing of a niche is extremely important. Studying of institutional anomalies (failures, dissonances, etc.) in regional economic systems, especially from positions of configuration approach isn't less significant.

Possibilities of practical use of post-institutional methodology in regional economics are connected with increase in level of an operationality of institutional approach and expansion of potential of its application as tools of strategic regulation of mesoeconomic processes. In particular, become possible, first, the argument of a complex of universal and territorial-specific recommendations about formation of institutional policy for governing bodies of the cities and regions; secondly, development of the system of direct and indirect indicators of institutional development of regional economies; thirdly, formation of conceptual bases, priority directions and model of the mechanism of regulation of the transaction sector of regional economy and its separate transaction industries. In general, increase (on the basis of methodology of post-institutional analysis) realism of studying of regional institutions and institutional changes will inevitably and positively affect regional economic policy, having created a scientific basis for refusal of obsolete and inefficient approaches.

\section{Acknowledgment}

This work was supported by Russian Foundation for Basic Research (project no. 18-010-00832).

\section{References}

[1] D.P. Frolov, I.V. Marushchak, Postinstitutionalism [Postinstitucionalizm]. Volgograd: Publ. Volgograd state University, 2017, 284 p.

[2] D.P. Frolov, "Methodological institutionalism 2.0: from institutions to institutional configurations" [Metodologicheskij institucionalizm 2.0: ot institutov - $\mathrm{k}$ institucional'nym konfiguracijam], Economic issues, 2016, No 7, pp. 147-160. 
[3] D.P. Frolov, A.S. Strekalova "Place marketing approach to governance of social-ecological clusters", Russia and the European Union. Development and Perspectives. Series Contributions to Economics. Cham, Switzerland: Springer, 2017, 489 p., pp. 315-319.

[4] D.P. Frolov, A.O. Inshakova and M.L. Davydova, "The Institutional Factors of Strategic Development and the Tactical Regulation of Nanotechology", European Research Studies Journal, 2017, vol. XX, no. 3, pp. 588-606.

[5] D.P. Frolov, Sarkisyan V.G., A.P. Karibov and A.S. Strekalova "Market-Oriented Approach to Management of Territorial Development: Discussion of Debatable Issues", Russia and the European Union. Development and Perspectives. Series Contributions to Economics. Cham, Switzerland: Springer, 2017, pp. 315-319. 